Cad.Est.Ling., Campinas, (44):105-118, Jan./Jun. 2003

\title{
EXPRESSÕES REFERENCIAIS - UMA PROPOSTA CLASSIFICATÓRIA
}

\author{
MÔNICA MAGALHÃES CAVALCANTE \\ (Universidade Federal do Ceará)
}

\begin{abstract}
In this work, we reflect about the suggested criteria in literature to identify different kinds of anaphorics and deictics, according to their referential function, meaning features and manifestation forms. Privileging remission parameter, we divide these referential elements into two major groups: in one of them, there are expressions introducing new referents in discourse universe without any referential continuity; in the other group, there are expressions with referential continuity, either because they are explicitly evocated or because they are inferible.
\end{abstract}

\section{INTRODUÇÃO}

Vai longe o tempo em que, em Lingüística Textual, tratar de elos coesivos referenciais se reduzia a deitar os olhos sobre o nível estrito da sintagmática imanente do texto. A coesão referencial deixou de ater-se à resolução de aspectos da estruturação concreta dos nexos internos (como em Halliday-Hasan, 1976, por exemplo, e em Koch, 1989) para integrar-se a outras dimensões pragmático-discursivas operantes na configuração semântica da coerência.

A partir de uma visão de que toda análise lingüística que desconsidere a interação de variados contextos (incluindo-se nisso o cotexto, a situação imediata de comunicação, o conhecimento sócio-cultural e o partilhamento sócio-cognitivo dos interlocutores) se torna insuficiente e insatisfatória, propomos, neste trabalho, um quadro classificatório dos processos referenciais e suas formas coesivas, que se erija desse pressuposto fundamental e da concepção, muito bem substanciada nas palavras de Koch (2002:79), de que "a realidade é construída, mantida e alterada não somente pela forma como nomeamos o mundo, mas, acima de tudo, pela forma como, sociocognitivamente, interagimos com ele".

Tal perspectiva, que adotamos por inteiro, concebe o referente como uma representação "fabricada" do que existe na realidade, não como o objeto mundano em si mesmo (ver Mondada, Dubois, 1995 e Apothéloz, 1995), e supõe uma ação mútua entre língua e práticas sociais, em que, numa trajetória circular e ininterrrupta, "a práxis cria a estereotipia de que depende a língua e esta, por sua vez, materializa e reitera a práxis" (cf. Blikstein, 1983:80). 


\section{A PROPOSTA}

Constituem expressões referenciais todas as formas de designação de referentes, as quais se diferenciam pelo modo como indicam ao "co-enunciador" (Maingueneau, 2001) como o enunciador pretende que ele identifique e interprete o referente. Nessa atividade essencialmente cooperativa (Grice, 1975), os "co-enunciadores" dispõem de diversas pistas, em parte convencionadas na própria língua, para reconhecer os diferentes espaços ou "campos dêiticos" (Bühler, [1934]1982) em que se situam os objetos para os quais construirão uma representação mental de referentes.

Sabemos que nem toda expressão referencial é anafórica ou dêitica, e essa verdade, sozinha, já cinde os elementos referenciais em dois grandes blocos: (i) os que introduzem novos referentes no "universo do discurso" (Lyons, 1977) sem promoverem nenhum tipo de continuidade referencial; e (ii) os que realizam a continuidade referencial de objetos presentes no universo discursivo, ou porque foram explicitamente evocados ou porque são dali inferíveis. Este trabalho é uma tentativa de agrupar, de maneira coerente, os subtipos que poderiam abrigar-se nesses dois blocos, a fim de suprir uma lacuna que reconhecemos existir nos estudos de referenciação: uma classificação geral de anafóricos e dêiticos.

\section{Introduções referenciais puras (sem continuidade)}

Diremos que há apenas introdução de referentes quando a expressão referencial instituir um objeto no discurso sem que nenhum elemento do contexto discursivo ou da situação imediata de comunicação o tenha evocado, como em (1):

(1) Se um homem bate na mesa e grita, está impondo controle. Se uma mulher faz o mesmo, está perdendo o controle. (Piadas da Internet)

Por sua função de não-continuidade referencial, podemos afirmar que expressões como "um homem", "na mesa" e "uma mulher" constituem formas não-anafóricas; e por não pressuporem o tempo/espaço dos interlocutores, são também não-dêiticas.

É possível, todavia, que certos introdutores de referentes apresentem uso dêitico em dado contexto. Fillmore ([1971]1997) subdivide os dêiticos em pessoais, temporais, espaciais e discursivos (textuais), mas é preciso acrescer a esse esquema os dêiticos memoriais (o fenômeno dos dêiticos da memória já foi tratado por diferentes autores, com outra terminologia; ver, por exemplo, Bühler, 1934; Lyons, 1977, Apothéloz, 1995). Dentre esses cinco tipos, importa agora observar que os dêiticos discursivos (textuais), como exemplificaremos adiante, não compõem o conjunto das introduções referenciais, mas o das continuidades, por remeterem a trechos do cotexto. Já os 
demais, de fato, apenas introduzem referentes no discurso, como podemos constatar pelos exemplos seguintes ${ }^{1}$ :

a) Dêiticos pessoais (apontam para os próprios interlocutores na situação de comunicação):

(2) As frases seguintes foram proferidas, realmente, por advogados e tiradas de registros oficiais de tribunais:

* Você tem filhos ou coisa do gênero???

* - Vou mostrar-lhe a Prova 3 e peço que reconheça a foto.

- Este sou $e u$.

- Você estava presente quando esta foto foi tirada? (Piadas da Internet)

b) Dêiticos temporais (pressupõem o tempo em que se dá o ato comunicativo ou o tempo em que a mensagem é enviada):

(3) Apresentada na última sexta-feira pela polícia como uma das autoras do assassinato de seus pais, ocorrido no mês passado, em São Paulo, Suzane Richthofen, de 19 anos, tem muito a ensinar sobre a atual geração de jovens de classe média. (Artigo de opinião, de Gilberto Dimenstein - Folha de São Paulo)

Os referentes de "na última sexta-feira" e de "no mês passado" só podem ser corretamente interpretados se forem apropriadamente ancorados na situação enunciativa, ou seja, se o interlocutor tiver ciência da data em que a matéria foi publicada no jornal, o que é bastante para lhes dar deiticidade.

1.2.3 Dêiticos espaciais (remetem ao lugar em que se acha o enunciador, ou pressupõem esse local):

(4) “Cantadas que não deram certo

Homem: Este lugar está vago?

Mulher: Está, e este aqui onde estou também vai ficar se você se sentar aí." (Piadas da Internet)

"Este lugar" e "este aqui onde estou" apontam para o espaço real em que se dá a conversa dos personagens e permitem ao leitor compreender que, dentro da comunicação que ali se efetiva, os objetos referidos estão fisicamente próximos ao falante.

1.2.4 Dêiticos memoriais (indicam que o referente tem acesso fácil na memória comum dos interlocutores e incentivam o destinatário a buscar ali a informação de que ele precisa):

${ }^{1}$ É importante lembrar, no entanto, que os usos dêiticos pessoais, temporais, espaciais e memoriais podem perfeitamente amalgamar-se a empregos anafóricos, numa estratégia textualizadora híbrida. Optamos por desgarrar os híbridos desta classificação para não onerar demais o quadro. 
(5) Tudo começou quando eu tinha uns 14 anos e um amigo chegou com aquele papo de 'experimenta, depois, quando você quiser, é só parar...' e eu fui na dele. Primeiro ele me ofereceu coisa leve, disse que era de 'raiz', 'da terra', que não fazia mal, e me deu um inofensivo disco do 'Chitãozinho e Xororó' e em seguida um do 'Leandro e Leonardo'. (crônica Drogas do submundo - autor desconhecido)

Note-se que a seleção da expressão "aquele papo de experimenta..." não é inocente no contexto: ela denuncia ao destinatário que o enunciador pressupõe que ele compartilhe o conhecimento do modo como as pessoas são incentivadas a mergulhar no mundo das "drogas". O discurso se constrói, em (5), em torno da analogia entre as drogas alucinógenas e a qualidade das músicas mais populares do Brasil de hoje. Para resgatar da memória do interlocutor a informação básica que engatilhará tal inferência, o enunciador se auxilia do demonstrativo ${ }^{2}$ de terceira pessoa aquele.

\section{Continuidades referenciais}

Ao contrário das introduções referenciais puras, que descrevemos até então, as continuidades referenciais ${ }^{3}$ fazem manter uma espécie de base de referencialidade, que se percebe por algum gatilho no co(n)texto. Para haver continuidade, não é obrigatório, com efeito, que exista sempre retomada total ou parcial de um mesmo referente, como nas anáforas diretas. Pode ser que a ligação se estabeleça apenas entre uma âncora e outro elemento cotextual introduzido pela primeira vez no texto, como nas anáforas indiretas e encapsuladoras.

Aqui é, pois, o reino das anáforas. Sugerimos que neste nicho se abriguem todas elas: diretas e indiretas, com dêiticos ou sem dêiticos. Esta proposta de reenquadramento apresenta a vantagem de preservar uma intuição comum, em Lingüística Textual, de que todo recurso referencial que remeta, no mínimo, a qualquer âncora do cotexto é, no fundo, anafórico. Não interessa se tal âncora é um antecedente correferencial, ou se é um outro referente distinto, ou se não constitui nem mesmo um referente, mas sim um conteúdo proposicional, como nos encapsulamentos. Também não importa que, além de exercer esse papel endofórico, certos recursos referenciais sejam simultaneamente dêiticos, cumprindo, assim, uma estratégia referencial híbrida: seriam, neste último caso, simplesmente anafóricos com dêiticos. Dessa maneira, e por bem de uma classificação mais simples e menos flutuante, deixaríamos à margem, para serem alocadas em outro nicho - o das introduções referenciais puras tratadas acima todas as ocorrências de motivação situacional, mas não co(n)textual, pois seriam, de resto, apenas dêiticas.

${ }^{2}$ Uma reflexão mais aprofundada sobre a importância da escolha dos determinantes nos processos referenciais coesivos exigiria, no entanto, aqui, um espaço de discussão mais amplo, que nos desviaria do objetivo maior de chegar a uma síntese classificatória dos referenciadores.

${ }^{3}$ Não estamos tratando as continuidades como "manutenções referenciais" para não incorrermos no equívoco de restringi-las aos casos de retomada correferencial. 


\subsection{Anáforas com retomada}

Diferentemente de Marcuschi e Koch (1998), reservaremos ao termo retomar apenas a idéia de correferencialidade ou de recuperação parcial dos referentes. Estes seriam os modelos mais prototípicos de anáfora. O que estamos entendendo por retomada parcial se aplica ao emprego de repetições do antecedente, determinadas por quantificadores, como "os topiqueiros.... dois deles...", ou "alguns deles" etc.

Até este ponto do estudo, elegemos um critério homogêneo de classificação: o da função referencial; a análise agora se tornará mais complexa, de vez que contemplará também dois parâmetros de outra ordem: um diz respeito a traços de significação e de denotação, em que distinguiremos entre fenômenos de co-significação e fenômenos de recategorização lexical; outro diz respeito a traços formais, em que relacionaremos a descrição referencial aos elos coesivos identificados por Koch (1989; e Vilela, Koch, 2001): as formas remissivas gramaticais livres e as formas remissivas lexicais.

Seguindo esses princípios, e obedecendo sempre à seguinte ordem hierárquica: função referencial, traços de significado e características formais, dividiremos as anáforas, em primeiro lugar (pelo parâmetro da referencialidade), em dois grupos aquelas que operam uma retomada, que pode ser total (correferencial) ou parcial, e aquelas que não retomam referentes, apenas fazem algum tipo de remissão ao co(n)texto; este último subgrupo engloba as anáforas indiretas e os encapsulamentos.

2.1.1 Anáfora correferencial (total): abrange qualquer processo em que duas expressões referenciais designam o mesmo referente, não importando o fato de a expressão anafórica remeter retrospectivamente ou prospectivamente. Quanto ao significado, as correferências podem ser de três tipos: co-significativas, recategorizadoras ou nem uma coisa nem outra.

2.1.1.1 Anáfora correferencial co-significativa: dá-se pela reiteração de termos, como no caso do sintagma "o velho" em:

(6) $\mathrm{Na}$ embarcação desconfortável, tosca, apenas quatro passageiros. Uma lanterna nos iluminava com sua luz vacilante: um velho, uma mulher com uma criança e eu. $O$ velho, um bêbado esfarrapado, deitara-se de comprido no banco, dirigira palavras amenas a um vizinho invisível e agora dormia." (conto de Lygia Fagundes Telles - Protexto)

O conceito de co-significação é formulado em Marcuschi e Koch (1998) como um correlato da noção de recategorização lexical; trata-se de duas noções mutuamente excludentes. Neste trabalho, consideraremos que haja co-significação somente quando se empregarem repetições ou palavras sinônimas; e que haja recategorização lexical quando uma forma referencial for renomeada no discurso, a fim de se adaptar aos objetivos comunicacionais persuasivos do enunciador (ler Apothéloz, ReichlerBéguelin, 1997).

Nestas anáforas co-significativas e recategorizadoras, ficam incluídos os elos coesivos denominados por Koch (1989) como formas remissivas lexicais: grupos nominais definidos que fornecem instruções de conexão e instruções de sentido. Como 
mostramos em trabalho anterior (Cavalcante, 2002), a diferença entre as formas remissivas gramaticais e as lexicais se estabelece no âmbito do sentido e da denotação, não no âmbito da referência. Em razão disso, diremos que as formas remissivas lexicais do tipo expressões sinônimas ou quase-sinônimas e às repetições com ou sem mudança de determinante, na classificação de Koch, corresponderiam às anáforas correferenciais co-significativas. Os demais elos coesivos lexicais comporiam, quase todos, as anáforas recategorizadoras com retomada, como veremos abaixo. Vale antes ressaltar que tais anáforas, co-significativas e recategorizadoras, podem ambas exercer também função dêitica, operando, assim, como elementos híbridos: como anáfora e dêixis.

Ao contrário de (6), acima, em que o enunciador recuperou o referente já introduzido apenas repetindo a expressão referencial, os exemplos de (7) a (10) remodulam a forma de designação, transformando-a, ou seja, recategorizando-a, ou pela utilização de um termo superordenado, para que o enunciador se esquive de repetições estilisticamente indesejáveis, ou pela utilização de expressões com alguma carga avaliativa. Estas possibilidades correspondem às seguintes formas remissivas lexicais, de Koch: hiperônimos ou indicadores de classe, grupos nominais definidos e nomes genéricos, conforme se encontram exemplificados, respectivamente, em (7), (8) e (9).

\subsubsection{Anáfora correferencial recategorizadora:}

\section{a) por hiperônimo}

(7) Não deixe acumular água em pratos de vasos de plantas e xaxins. Na hora de lavar $o$ recipiente, passe um pano grosso ou bucha nas bordas para remover os ovos do mosquito que podem estar nas paredes ou no fundo do recipiente. Substitua a água dos vasos de plantas por areia grossa umedecida." (campanha contra a dengue divulgada em panfleto)

A expressão anafórica hiperonímica "o recipiente" constitui uma etiqueta para um conjunto mais amplo, que acolheria "vasos de plantas e xaxins" e outros elementos mais. Já as expressões definidas, abaixo, recategorizam aspectualizando um traço do antecedente.

\section{b) por expressão definida}

(8) SOBE

\section{CARLOS ALBERTO PARREIRA}

* O treinador tetracampeão do mundo voltou ao comando da seleção brasileira.

PAULO LACERDA

* O delegado que ajudou a desvendar o esquema de corrupção de PC Farias foi escolhido para dirigir a Polícia Federal. (Notas - Veja, 15/01/03)

Esta seleção de atributos, nas expressões definidas em grifo, pode ter fins diversos: acrescentar informações que particularizam o referente, ou destacar pontos de vista do enunciador sobre a entidade referida, ou as duas estratégias ao mesmo tempo. Observe-se que, nesta coluna sobe/desce, da revista Veja, geralmente se apresenta o nome próprio de quem está sendo focalizado, para logo depois retomar o referente 
recategorizando-o por um $\mathrm{SN}$ de função simultaneamente referencial e atributiva, ou, nas palavras, de Schwarz (2000), de "função temática e remática".

\section{c) por nome genérico}

(9) Dividimo-la em dois grupos de definições: num deles listamos as definições de cunho metafísico e psicológico; noutro, algumas de caráter mais lingüístico, em que se consideram os seguintes fatores: ênfase; escolha; características individuais (...). (artigo científico - Revista de Letras, 1996).

O nome fatores de algum modo classifica os três itens que virão em seguida. É válido, aqui, atentar para o fato de que o anafórico recategorizador, em (9), contém um dêitico - o adjetivo "seguintes" - que remete diretamente ao espaço físico do cotexto e representa, portanto, um híbrido. Um outro tipo de elemento anafórico e dêitico pode ser exemplificado por (10), em que anáfora correferencial se manifesta pelo dêitico isso.

\section{d) por pronome}

(10) Largo dos Leões - Então o Largo dos Leões é isso?... Essa porcaria!

- Mas você não queria tanto ver o Largo dos Leões? Aí está o Largo dos Leões.

- Não. Eu queria ver era o Laargo dos Le-õ-ões! Um que eu ouvi falar muito.

- Pois é este! (...)

- Não é, papai! O Largo dos Leões então é isso?!... (romance João Ternura, de Aníbal Machado)

Mas o fato mais curioso de (10) não reside no caráter híbrido e sim, na espécie de recategorização que o pronome demonstrativo realiza. Em primeiro lugar, não se trata de uma forma remissiva lexical, e sim, de uma forma remissiva gramatical. Todavia, a despeito de os pronomes não portarem conteúdo semântico suficiente para promover uma recategorização explícita, o demonstrativo neutro pode ser empregado com um valor pejorativo, como em (10), acompanhado de traços prosódicos que o ratifiquem. Situações como esta têm sido negligenciadas nos estudos sobre o assunto, mas se revelam, a nosso ver, recategorizações legítimas, pelas nuanças de afetividade do demonstrativo neutro, que dão ao referente um novo contorno.

Este caso dos demonstrativos não deve ser confundido com o das retomadas por pronomes pessoais, sempre abordadas na literatura como "co-significativas" (assim podemos verificar em Milner (1982), Apothéloz (1995), Marcuschi e Koch (1998), dentre outros), como se encontra exemplificado em (11). Cremos, no entanto, haver uma certa incoerência no que respeita ao tratamento de tais pronomes como "cosignificativos".

2.1.1.3 Anáfora não-co-significativa e não-recategorizadora (é formalizada por pronomes pessoais):

(11) Betsy esperou a volta do homem para morrer. 
Antes da viagem ele notara que Betsy mostrava um apetite incomum. (conto Betsy, de Rubem Fonseca)

Sempre se alegou, na Lingüística, que as formas pronominais divergiam das formas lexicais por seu baixo grau de significação, por sua função mais gramatical do que lexical, por seu traço dêitico ou representacional etc. Como, então, sustentar que o nome antecedente nominal e o anafórico pronominal são "co-significativos" se, por definição, é a peculiaridade de significados que os distingue? Julgamos mais adequado, por isso, considerar os pronomes pessoais anafóricos como não sendo nem recategorizadores, nem co-significativos.

\subsubsection{Anáfora parcial}

\subsubsection{Anáfora parcial co-significativa}

Para não confundir com as anáforas indiretas, que se instauram muitas vezes por uma relação de parte-todo, optamos por circunscrever estes casos às repetições do sintagma antecedente, precedidas de um quantificador, como em (12), ou de um adjetivo, imprimindo ao anafórico a idéia de parte de um conjunto não-unitário. Por vezes, o nome nuclear é elidido por economia lingüística e por razões de estilo, como em "um", em (13), e "o último", em (14):

\section{a) por $\mathrm{SN}$}

(12) Bifes com molho de tomate

Ingredientes

1/4 de xícara de óleo; $1 \mathrm{~kg}$ de bifes de vaca ou de vitela, cortados finos (...)

Modo de fazer

Numa frigideira de 25 ou $30 \mathrm{~cm}$ de diâmetro, esquente o óleo em fogo forte e frite poucos bifes de cada vez, por 2 ou 3 minutos de cada lado ou até o ponto desejado. (receita - Protexto)

\section{b) por indefinido ou por numeral}

(13) * Dois litros de leite atravessaram a rua e foram atropelados. Um deles morreu e o outro não, por quê? R: Porque um deles era Longa Vida.

* Estavam dois caminhões voando. Até que um disse: - Peraí, caminhão não voa! Um caiu no chão mas o outro continuou voando. Por quê? R: Porque era um caminhão-pipa. (Piadas da Internet)

\section{c) por adjetivo}

\section{(14) Vereadores renunciam ao mandato}

Após Lucílvio Girão (PL) renunciar ao mandato de vereador, na última quinta-feira, para assumir seu assento na Assembléia Legislativa, ontem foi a vez dos demais vereadores eleitos apresentarem suas cartas de demissão à Câmara Municipal de Fortaleza. $O$ último a enviar o documento foi o Jaziel Pereira (PHS). (notícia - jornal Diário do Nordeste)

Encerram-se aqui as anáforas com retomada, total ou parcial. Descreveremos, agora, a segunda grande subdivisão das anáforas, que abarca todas as situações em que 
o referente do anafórico não é idêntico, ou quase idêntico, a um antecedente pontual do co(n)texto.

\subsection{Anáforas sem retomada}

As anáforas indiretas foram acordadas na literatura como tendo duas características fundamentais, porém não únicas: (i) a não-correferencialidade e (ii) a introdução de um referente novo sob o modo do conhecido. Os partidários de uma posição semanticista, como Kleiber $(1991,2001)$, restringem as anáforas indiretas aos tipos associativos, marcados por aspectos léxico-estereotípicos. Mas seguiremos, neste trabalho, a visão mais estendida de anáfora indireta, tal como tem sido tratada por Apothéloz e Reichler-Béguelin (1999), Schwarz (2000), dentre outros, que, como Koch (2002) e Marcuschi (2000).

As anáforas indiretas são, assim, continuidades referenciais sem retomada, apenas com remissão a uma âncora no co(n)texto. A espécie mais representativa de anáfora indireta é a que se instala por uma relação de meronímia (Kleiber, 2001), ou relação de ingrediência, como se vê em (14), que é tipicamente associativa.

\subsubsection{Anáfora indireta}

\subsubsection{Anáfora indireta com categorização de um novo referente}

(15) Modo de preparar:

Coloque o amendoim em uma assadeira e leve ao forno médio por 30 minutos. Mexa sempre até que o amendoim esteja torrado e a pele saindo com facilidade. (receita - Protexto)

O anafórico "a pele" não retoma a âncora "o amendoim"; embora seja parte dele, é tomado no texto como uma entidade autônoma, daí por que tem sido encarado como um referente novo, categorizado pela primeira vez e facilmente associável ao seu todo. Cremos que estas anáforas indiretas meronímicas se localizem num nível muito próximo das anáforas diretas. Bastaria, aliás, que inseríssemos um determinante possessivo para que a literatura o elegesse como anáfora direta correferencial.

De modo geral, porém, as ligações inferenciais que se elaboram pelo emprego das anáforas indiretas são sempre cognitivamente mais complexas do que as relações entre a anáfora direta e seu antecedente. Há como que um percurso maior de raciocínio que só se completa com as informações supostamente presentes em esquemas mentais culturalmente compartilhados. Acreditamos que haja diferentes graus de complexidade na ativação desses esquemas mentais em que as associações serão estabelecidas. Se, em (15), por exemplo, é relativamente simples inferir, a partir do adjetivo "brasileiro", o local Brasil, que seria o antecedente implícito para anáfora indireta "este país", já em (16), a inferência não se constrói por uma relação lexical tão imediata.

(15) Há dois anos nacionalizei-me brasileiro por opção e pelo amor que tenho por este país. (Carta do leitor - Veja, 15/01/03)

(16) Decifra-me ou te mato

Essa é a radicalidade do consumismo. Viver é satisfazer imediatamente os desejos. Suzane Richthofen disse que, ajudada pelo namorado, matou por amor. O pai, um engenheiro, e a mãe, 
uma psiquiatra, não gostavam do namorado e estariam inviabilizando a relação. (Artigo de opinião, de Gilberto Dimenstein - Folha de São Paulo)

Em (16), o leitor precisa recuperar da memória a pressuposição pragmática de que, se existe um namorado, pode-se então falar de uma ligação amorosa entre os dois personagens do texto e, portanto, de uma "relação" - um termo muito em voga atualmente.

Entendemos que, em geral, as anáforas indiretas, por introduzirem uma entidade nova no discurso, categorizam novos referentes, mas a recategorização lexical também é possível quando ela se realiza implicitamente, como mostraremos no item seguinte.

\subsubsection{Anáfora indireta com recategorização lexical implícita}

Marcuschi (1998) chamou a atenção, pela primeira vez, para o fenômeno dos antecedentes implícitos (ou anáfora esquemática), reconsiderando-o, mais tarde (Marcuschi, 2000), como um dos tipos de anáfora indireta. Exemplos do autor:

(17) A equipe médica continua analisando o câncer do Governador Mário Covas. Segundo eles, o paciente não corre risco de vida. (Marcuschi, 1998) ${ }^{4}$

(18) Os alunos da primeira série aprenderam as vogais. Ela utilizou um método novo para ensiná-los. (idem)

Acreditamos que de fato se dê, em (17), uma recategorização lexical que transforma "a equipe médica" em "os médicos", e esta modificação é empreendida implicitamente. Em seguida, verifica-se um processo de pronominalização de "os médicos" em "eles", explícito na superfície textual. É de Apothéloz e Reichler-Béguelin a denominação de recategorização lexical implícita para as ocorrências que sempre conhecemos como silepse.

Em (18), no entanto, a situação nos parece diversa. Não afirmaríamos que aí se constrói uma recategorização, mas uma categorização lexical (tal como em 16), em que, dentro de um esquema mental que se abre para "alunos" e "aula", é muito pertinente incluir "professora", numa referenciação implícita, e depois representá-la pelo pronome "ela", sem necessidade de maiores explicações num contexto de informalidade. Julgamos, portanto, que não se trate de recategorização lexical, uma vez que não houve exatamente a transformação de uma expressão nominal designadora em outra.

Algo bem diferente nos parece acontecer em (19), abaixo, em que transcorrem dois fenômenos concomitantes: um de categorização de um referente novo sob o modo do conhecido e outro de recategorização, ou transformação da forma de designação esperada em outra inesperada.

\footnotetext{
${ }^{4}$ Trabalho apresentado num Encontro sobre Lingüística na PG em Lingüística da UFJF, Juiz de Fora, em dezembro de 1998.
} 


\subsubsection{Anáfora indireta com recategorização lexical}

(19) Qualquer que seja a chuva desses campos devemos esperar pelos estios; e ao chegar os serões e os fiéis enganos amar os sonhos que restarem frios.

Porém se não surgir o que sonhamos e os ninhos imortais forem vazios, há de haver pelo menos por ali os pássaros que nós idealizamos.

Feliz de quem com cânticos se esconde e julga tê-los em seus próprios bicos, e ao bico alheio em cânticos responde.

E vendo em torno as mais terríveis cenas, possa mirar-se as asas depenadas e contentar-se com as secretas penas. (poema de Jorge de Lima)

Em (19), a âncora "pássaros que nós idealizamos" autoriza a categorização de anáforas indiretas como "seus próprios bicos", "ao bico alheio", "cânticos, assim como favorece a introdução de "asas" e "penas", pelo mesmo processo meronímico. Entretanto, no lugar de simplesmente "asas" e "penas", ocorre uma recategorização por "asas depenadas" e "secretas penas", que, neste discurso literário, tem a finalidade de ratificar a metáfora do pássaro, reconstruindo os sentidos e os referentes dos termos em grifo.

Outras possibilidades de anáfora indireta têm sido caracterizadas recentemente por Kleiber (2001), numa perspectiva essencialmente semântico-lexical. Pelas restrições teórico-metodológicas que fazemos ao modelo, e pela falta de uma descrição melhor do que a do autor, deixamos de considerá-lo no presente estudo.

Encerraremos esta proposta com a análise de um fenômeno que costuma ser aquartelado nos tipos de anáforas indiretas, por partilharem com elas o traço de nãocorreferencialidade e de introdução de um referente novo no discurso. Contudo, nossa posição é que tais anáforas, que chamaremos de encapsuladoras, se situam numa zona fronteiriça, que faz a interseção entre as anáforas diretas e as indiretas.

2.2.2 Anáfora encapsuladora (meio direta, meio indireta - rótulos, quando por $\mathrm{SN}$ )

Os encapsulamentos foram investigados por Francis (1986; 1994), por Conte (1996) e, no Brasil, por Koch (2002 e em outros lugares), por Zamponi (2001) e por Cavalcante $(2000 ; 2001$ e 2002). Encapsular consiste em resumir proposições do discurso empacotando-as numa expressão referencial, que pode ser um sintagma nominal (o qual tem rececido a denominação de "rótulo" - Francis, 1994), ou pode ser um pronome, geralmente demonstrativo. Assim se vê em (20):

(20) Um dos pontos de discussão no governo do PT diz respeito à extensão da jornada de trabalho. Por sugestão da CUT, estuda-se a hipótese de apresentar um projeto de lei reduzindo a carga semanal de trabalho das atuais 44 horas para 40. A idéia é inspirada no modelo europeu, principalmente o francês, e tem um objetivo principal: se as pessoas trabalharem menos, mais gente pode ser contratada. Um estudo sobre $o$ assunto realizado pelo sociólogo José Pastore mostra que $a$ estratégia pode não funcionar. (reportagem - Veja, 15/01/03)

Todas as anáforas encapsuladoras sublinhadas resumem uma porção textual e rotulam-na, indicando ao co-enunciador como se espera que o conteúdo resumido seja interpretado. Como notamos, não existe, com efeito, um antecedente pontual a que os 
encapsuladores possam remeter, razão por que poderiam ser classificados como anáforas indiretas. Porém, temos que admitir que, à semelhança de uma anáfora direta, os encapsuladores recuperam (sem retomar) o que há no co(n)texto. Esta natureza ambígua do fenômeno é que nos leva a preferir as anáforas encapsuladoras como um tipo à parte.

Por fim, sugerimos que se incluam entre as anáforas encapsuladoras os casos tratados na literatura como dêiticos discursivos. Em Cavalcante (2000), descrevemos os dêiticos discursivos como elementos que apresentam, a um só tempo, três características: (a) o encapsulamento, pelo qual o conteúdo resumido ganha estatuto de referente e é categorizado ou como pró-forma ou como rótulo; (b) o procedimento dêitico, pelo qual são orientados os focos de atenção dos interlocutores, por causa da presença de um dêitico; (c) a pressuposição do posicionamento do falante ou do destinatário na situação real de comunicação, também devido ao dêitico.

Hoje, admitimos que o único divisor de águas entre as anáforas encapsuladoras e os dêiticos discursivos é o acréscimo de um elemento dêitico. Por isso, sem negar a importante função cognitivo-discursiva que o traço dêitico soma à função representacional das anáforas, cremos ser mais coerente considerar os dêiticos discursivos como mais um tipo de híbrido: um anafórico dêitico, que tem o atributo especial de encapsular, como bem notou Ciulla (2002).

\subsubsection{Anáfora encapsuladora com dêitico (meio direta, meio indireta; híbrido- DD)}

As anáforas encapsuladoras com dêitico, ou dêiticos discursivos, podem manifestar-se por pronomes demonstrativos ou por sintagmas nominais; neste último caso, constituem rótulos com dêitico, tal como se vê, respectivamente, em (21) e (22).

\subsubsection{1 por demonstrativo}

(21) Mas nesse momento a recordação do homem não a angustiava e, pelo contrário, trazia-lhe um sabor de liberdade há doze anos não sentido. Porque seu marido tinha uma propriedade singular: bastava sua presença para que os menores movimentos de seu pensamento ficassem tolhidos. A princípio, isso lhe trouxera certa tranquiilidade (...) (conto A fuga, de Clarice Lispector)

\subsubsection{2 por $\mathrm{SN}$ (anáfora-rótulo com dêitico)}

(22) Veja - Uma mulher que trabalha o dia inteiro, cuida de filhos, tem de resolver problemas da casa nem sempre consegue arranjar tempo para praticar esporte. O que fazer para resolver esse dilema? (entrevista - Veja, 15/01/03)

\section{A SÍNTESE}

Muitos dos fatos lingüísticos referenciais que discutimos neste trabalho já foram alvo de intensas discussões, sobretudo quando se toca na delicada separação entre anáfora e dêixis. Em vista da co-existência destes dois parâmetros não mutuamente exclusivos - a função endofórica da anáfora e o caráter intersubjetivo da dêixis -, as 
flutuações terminológicas em torno dos elementos referenciais têm sido um grande entrave nas pesquisas de referenciação. Temos esperança de que a proposta aqui descrita alicerce sugestões melhores e mais amplas.

\section{REFERÊNCIAS BIBLIOGRÁFICAS}

APOTHÉLOZ, Denis. (1995). Rôle et fonctionnement de l'anaphore dans la dynamique textuelle. Tese (Doutorado) - Université de Neuchâtel.

APOTHÉLOZ, D. \& REICHLER-BÉGUELIN, M. J. (1995). Construction de la référence et strategies de designation. In: BERRENDONNER \& REICHLER-BÉGUELIN. p.227-71.

. (1999). Interpretations and functions of demonstrative NPs in indirect anaphora. Journal of Pragmatics, 31. p. 363-97.

BLIKSTEIN, Izidoro. (1983). Kaspar Hauser ou A fabricação da realidade. São Paulo: Cultrix.

BÜHLER, Karl. (1982). The deictic field of language and deictic words. In: JARVELLA, R.J.; KLEIN, W. (eds.) Speech, place and action: studies in deixis and related topics. New York: John Wiley and Sons. p. 9-30.

CAVALCANTE, Mônica M. (2000). Expressões indiciais em contextos de uso: por uma caracterização dos dêiticos discursivos. Recife, 205p. Tese /Doutorado em Lingüística/ - Universidade Federal de Pernambuco (UFPE).

. Demonstrativos - uma condição de saliência. /Conferência apresentada por ocasião do II Congresso Internacional da ABRALIN - Fortaleza, 2001/.

. Dêiticos discursivos - um caso especial de referência indireta? /Comunicação apresentada no $50^{\circ}$. Seminário do GEL. São Paulo: USP, 2002/.

CIULlA, A. (2002). A referenciação anafórica e dêitica - com atenção especial para os dêiticos discursivos. Fortaleza, 104p. Dissertação /Mestrado em Lingüística/ - Universidade Federal do Ceará UFC).

CONTE, Maria-Elisabeth. (1996). Anaphoric encapsulation. Belgian Journal of linguistics, 10, p. 1-10.

FILLMORE, C. (1997). Lectures on deixis. California: CSLI Publications.

FRANCIS, Gill. (1994). Labelling discourse: an aspect of nominal-group lexical cohesion. In: COULTHARD, M. Advances in written analysis. London and New York: Ed. Routledge, p. 83-101.

GRICE, Paul. (1975). Logic and conversation. In: COLE, P.; MORGAN, J. L. (orgs.). Syntax and semantics. New York: Academic Press. v. 2.

HALLIDAY, M.A.K. \& HASAN, R. (1976). Cohesion in spoken and written english. Londres: Longman.

KLEIBER, G. et alii. (1991). L'anaphore associative: aspects linguistiques. In: SCHNEDECKER, C. et alii. L'anaphore associative (aspects linguistiques, psycholinguistiques et automatiques). Paris: Faculté des Lettres et Sciences Humaines, p. 5-64.

KLEIBER, G. (2001). L'anaphore associative. Paris: Presses Universitaires de France.

KLEIN, W. (eds.) (1982). Speech, place and action: studies in deixis and related topics. New York: John Wiley and Sons. p. 9-30. 
KOCH, I.G.V. (1989). A coesão textual. São Paulo: Contexto. (2002). Desvendando os segredos do texto. São Paulo: Cortez.

KOCH, I.G.V. \& MARCUSCHI, L.A. (1998). Processos de referenciação na produção discursiva. DELTA, $14, \mathrm{n}^{\circ}$ especial.

LYONS, John. (1977). Semantics. London: Cambridge University Press, 2 v.

MARCUSCHI, L.A. (2000). Anáfora indireta: o barco textual e suas âncoras. /Texto remetido para publicação nos anais do Congresso da CelSul. Curitiba.

MILNER, J-C. (1982). Ordres et raisons de la langue. Paris: Seuil.

MONDADA, Lorenza \& DUBOIS, Danièle. (1995). Construção dos objetos do discurso e categorização: uma abordagem dos processos de referenciação. TRANEL (Travaux neuchâtelois de linguistique), $\mathrm{n}^{\circ}$ 23. p. $273-302$.

SCHWARZ, M. (2000). Indirekte Anaphern in Texten. Tübingen: Niemeyer.

VILELA, Mário \& KOCH, Ingedore Villaça. (2001). Gramática da língua portuguesa. Coimbra: Almedima.

ZAMPONI, Graziela (2001). O determinante demonstrativo em sintagmas nominais /Conferência apresentada por ocasião do II Congresso Internacional da ABRALIN - Fortaleza. 